\title{
Wavelength influence in sub-pixel temperature retrieval using the dual-band technique
}

\author{
Valerio Lombardo, Luca Merucci and Maria Fabrizia Buongiorno \\ Istituto Nazionale di Geofisica e Vulcanologia, Roma, Italy
}

\begin{abstract}
The thermal model proposed by Crisp and Baloga (1990) for active lava flows considers thermal flux as a function of the fractional area of two thermally distinct radiant surfaces. In this model, the larger surface area corresponds to the cooler crust of the flow and the other, much smaller to fractures in the crust. These cracks temperature is much higher than the crust one and approaches the temperature of the molten or plastic interior flow. The dual-band method needs two distinct SWIR (short wave infrared) bands to formulate a two equations system from the simultaneous solution of the Planck equation in each band. The system solutions consist in the crust temperature and the fractional area of the hot component. The dual band technique originally builds on data acquired by sensors (such as Landsat TM) with two SWIR bands only. The use of hyperspectral imaging spectrometers allows us to test the dual-band technique using different wavelengths in the SWIR range of the spectrum. DAIS 7915 is equipped with 40 bands into the range $1.54-2.49 \mu \mathrm{m}$ which represent potential input in dual band calculation. This study aims to compare results derived by inserting assorted couples of wavelengths into the equation system. The analysis of these data provides useful information on dual-band technique accuracy.
\end{abstract}

Key words remote sensing - volcanoes - dual-band DAIS sensor - hyperspectral analysis

\section{Introduction}

«Dual-band» is a remote-sensing technique used to determine the thermal structure of active lava flows. Following Crisp and Baloga (1990), we consider a two thermal components model: the first component is the cooler crust of the flow and the second one is the smaller surface corresponding to hot cracks. We suppose the cracks temperature $T_{h}$ to be related to the molten core of the flow (Oppenheimer, 1993b).

Mailing address: Dr. Valerio Lombardo, Istituto Nazionale di Geofisica e Vulcanologia, Via di Vigna Murata 605, 00143, Roma, Italy; e-mail: lombardo@ingv.it
The dual band technique allows us to estimate the crust temperature $T_{c}$ and the fractional area of hot cracks $f_{h}$, once we have set $T_{h}$ as boundary condition. A value of $1080^{\circ} \mathrm{C}$ is suitable for Etnean lavas according to in situ measurements (Gauthier, 1973; Archambault and Tanguy, 1976; GVN, 1993, 1996; Calvari et al., 1994). This method requires a spectrometer equipped with two distinct SWIR bands $\left(\beta_{1}, \beta_{2}\right)$ to formulate a system of two equations

$$
\left\{\begin{array}{l}
\operatorname{Rad}_{1}=f_{h}\left(R_{h 1}\right)+\left(1-f_{h}\right) R_{c 1} \\
\operatorname{Rad}_{2}=f_{h}\left(R_{h 2}\right)+\left(1-f_{h}\right) R_{c 2}
\end{array}\right.
$$

where $\operatorname{Rad}_{1}$ and $\operatorname{Rad}_{2}$ are respectively the total radiance detected by the sensor in band $\beta_{1}$ and $\beta_{2}, R_{h} x$ is the radiance of the hot crack component in band $x$ ( $x=\beta_{1}$ or $\beta_{2}$ in our case), $R_{c} x$ is the radiance of the cooler crust component in band $x$ and $f_{h}$ is the fractional area of the pixel with the hottest temperature $T_{h}$. Originally pro- 
Table I. Main features of the DAIS sensor.

\begin{tabular}{|c|c|c|}
\hline \multicolumn{3}{|c|}{ Dais characteristics } \\
\hline \multicolumn{3}{|c|}{ Wavelength range: $400-12600 \mathrm{~nm}, 79$ bands } \\
\hline Wavelength range & Bandwith & Detector \\
\hline 1) $400-1000 \mathrm{~nm}, 32$ bands & $15-30 \mathrm{~nm}$ & $\mathrm{Si}$ \\
\hline 2) $1500-1800 \mathrm{~nm}, 8$ bands & $36 \mathrm{~nm}$ & $\mathrm{InSb}$ \\
\hline 3) $2000-2500 \mathrm{~nm}, 32$ bands & $20 \mathrm{~nm}$ & $\mathrm{InSb}$ \\
\hline 4) $3000-5000 \mathrm{~nm}, 1$ bands & $2.0 \mu \mathrm{m}$ & MCT \\
\hline 5) $8000-12600 \mathrm{~nm}, 6$ bands & $0.8 \mu \mathrm{m}$ & MCT \\
\hline
\end{tabular}

Main radiometric parameters

Dynamic range: 15 bit (no gain settings).

Sensitivity Vis/Nir: NER $<0.0001 \mathrm{mWcm}^{-2} \mathrm{sr}^{-1} \mathrm{~nm}^{-1}$. Swir: NER $<0.00005 \mathrm{mWcm}^{-2} \mathrm{sr}^{-1} \mathrm{~nm}^{-1}$. MIR/TIR: NET $<0.1 \mathrm{~K}$.

Main geometric parameters

IFoV: $3.3 \mathrm{mrad}$ ( 2.5 or $5.0 \mathrm{mrad}$ optical).

Swath angle $\max \pm 39^{\circ}$ (depending on aircraft).

Pixels per line: 512 .

posed by Dozier (1981), this technique has been successfully applied by several authors (Pieri et al., 1990; Oppenheimer, 1991; Oppenheimer et al., 1993a-c; Harris et al., 1999; Flynn et al., 2001; Wright et al., 2001) to estimate the surface thermal structure of aa and pahoehoe lava-flows, as well as lava domes and lakes (Oppenheimer, 1993a; Wooster et al., 2000). The dual-band technique was at first applied to data collected by multi-spectral sensors such as Landsat TM and AVHRR. These sensors include a small number of bands in the SWIR region of the spectrum useful in dual-band calculation (in some cases just two bands).

Therefore, we cannot validate the accuracy of our solutions considering the effect of the wavelength choice. Hyperspectral sensors have many more bands available in the SWIR region. The DAIS instrument consists of four spectrometers named VIS-NIR, SWIR-1, SWIR-2 and Thermal, covering a spectral range of 0.4 $\mu \mathrm{m}-12.6 \mu \mathrm{m}$ with a total of 79 bands (see table I for more details). The constraints of lava temperature are well represented by II SWIR-1 and III SWIR-2 spectrometers. These sensors are equipped with 37 bands in the range $1.54 \mu \mathrm{m}$ $2.49 \mu \mathrm{m}$ that can be input into the dual band system calculations. A further remarkable question originates from the hyperspectral technology: how does the band wavelength choice affects the dual-band solutions?

\section{Data reduction}

Hyperspectral airborne images of June 1996 volcanic eruption of Mt. Etna (Eastern Sicily, Italy) were collected using the DAIS 7915 spectrometer during the multi-sensor campaign of Italian volcanic systems (Horne et al., 1997). The 1996 Mt. Etna eruptive activity was imaged on, July 16th and 18th. In this study, we use the July 16th dataset to test dual-band technique as function of the wavelength. Figure 1 shows the DAIS flight line and the zoom of the Etnean craters area. On July 16th three craters were ac-

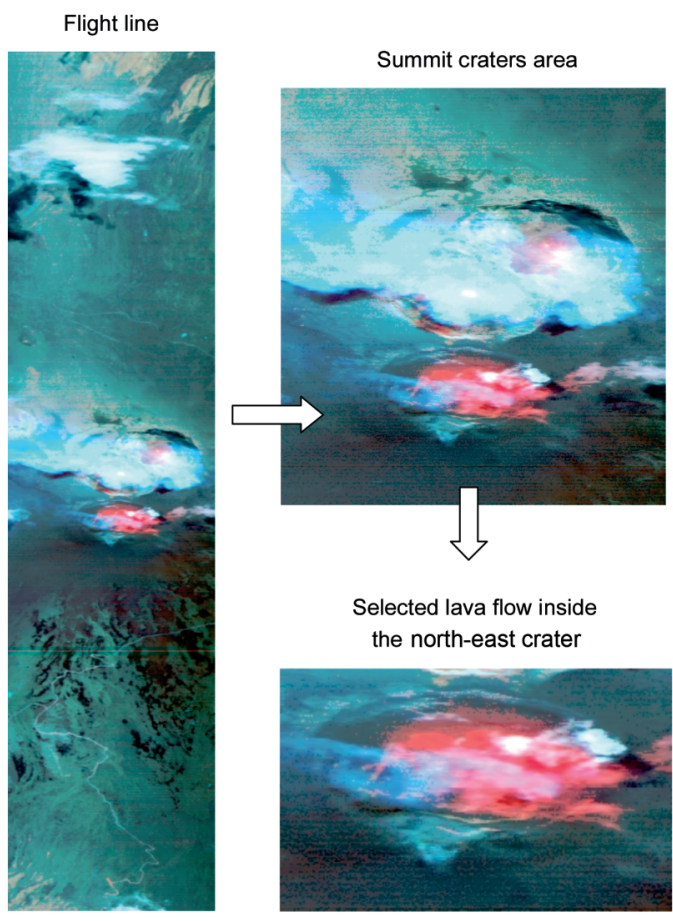

Fig. 1. DAIS flight line imaged on 16th July 1996. 
tive: the Northern-East, Bocca Nuova and Voragine (GVN, 1996). We applied the dual-band calculation to the pixels of the lava pond located within the Northern-East crater selecting the described area on the image by means of a suitable mask. Initially we used DAIS band 36 and 57 corresponding to a center-band of 1.637 and $2.215 \mu \mathrm{m}$ respectively. We needed a pair of bands to refer to in our comparison and we chose those wavelengths because they are closer to the 2 corresponding Landsat TM SWIR bands (band 5 and 7 corresponding to a centerband of 1.65 and $2.22 \mu \mathrm{m}$ respectively). Obviously the chosen wavelengths fall within the two main atmospheric windows making the correction of data for the atmospheric contribution much easier.

\section{Data analysis}

In order to assess the influence of the bands' wavelength on the dual band system solutions, we performed the calculation using every band of the spectrometer II combined with each band of the III. Table II lists the band number and the corresponding center band wavelength of the second and third DAIS spectrometers (SWIR-1 and SWIR-2).

For any couple of bands of the two SWIR spectrometers the convergent solutions of the algorithm give an estimation of $T_{c}$ and $f_{h}$. The following results apply to the whole set of DAIS band pairs chosen from SWIR-1 and SWIR-2 spectrometers. For a clearer graphic visualization we have represented the results obtained by varying the SWIR-2 band versus the same SWIR-1 band, namely band 36 that for reference corresponds to the band 5 of Landsat TM.

The estimated values of $f_{h}$ range between 0.000 and $0.013 \%$ while values of $T_{c}$ range between 100 and $500^{\circ} \mathrm{C}$ for non-saturated pixels that in this case represent the $96 \%$ of the whole image. Figure 2 shows the $f_{h}$ solutions calculated for each pixel and plotted together as a function of the DAIS band. Figure 4 offers a similar representation for the $T_{c}$ solutions where a decreasing $T_{c}$ trend appears for increasing wavelength.

We obtain a clearer view of the ensemble of $f_{h}$ solutions if we subtract for each pixel the
Table II. SWIR-1 and SWIR-2 band list.

\begin{tabular}{|c|c|c|c|}
\hline \multicolumn{2}{|c|}{$\begin{array}{l}\text { Spectrometer II, } \\
\text { SWIR-1 }\end{array}$} & \multicolumn{2}{|c|}{$\begin{array}{c}\text { Spectrometer III, } \\
\text { SWIR-2 }\end{array}$} \\
\hline Band & $\mu \mathrm{m}$ & Band & $\mu \mathrm{m}$ \\
\hline 33 & 1.543 & 41 & 1.962 \\
\hline 34 & 1.574 & 42 & 1.972 \\
\hline 35 & 1.606 & 43 & 1.985 \\
\hline 36 & 1.637 & 44 & 1.998 \\
\hline 37 & 1.669 & 45 & 2.013 \\
\hline 38 & 1.699 & 46 & 2.030 \\
\hline 39 & 1.727 & 47 & 2.047 \\
\hline \multirow[t]{25}{*}{40} & 1.754 & 48 & 2.064 \\
\hline & & 49 & 2.081 \\
\hline & & 50 & 2.099 \\
\hline & & 51 & 2.116 \\
\hline & & 52 & 2.133 \\
\hline & & 53 & 2.150 \\
\hline & & 54 & 2.165 \\
\hline & & 55 & 2.179 \\
\hline & & 56 & 2.191 \\
\hline & & 57 & 2.215 \\
\hline & & 58 & 2.234 \\
\hline & & 59 & 2.251 \\
\hline & & 60 & 2.264 \\
\hline & & 61 & 2.279 \\
\hline & & 62 & 2.291 \\
\hline & & 63 & 2.306 \\
\hline & & 64 & 2.318 \\
\hline & & 65 & 2.331 \\
\hline & & 66 & 2.344 \\
\hline & & 67 & 2.357 \\
\hline & & 68 & 2.372 \\
\hline & & 69 & 2.386 \\
\hline & & 70 & 2.400 \\
\hline & & 71 & 2.412 \\
\hline & & 72 & 2.426 \\
\hline
\end{tabular}

mean $\left\langle f_{h}>\right.$ to the $f_{h}$ values calculated on each SWIR-2 band. Figure 3 shows this deviation from the mean $\left\langle f_{h}\right\rangle$ as function of the DAIS band number. This calculation yields more stable results with a maximum deviation of $0.002 \%$ for 26 of the 32 channels of the third spectrometer. 


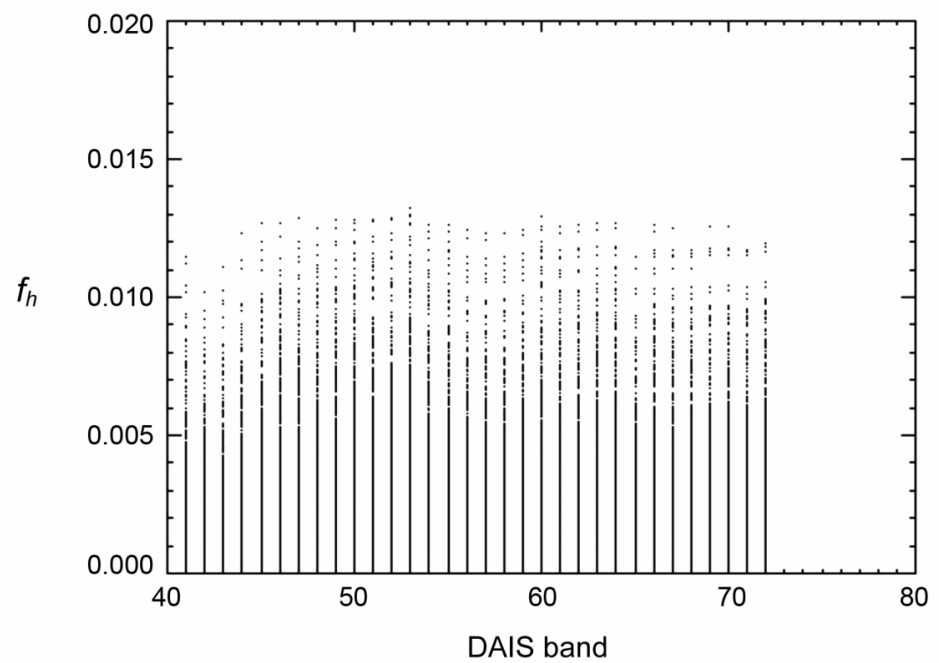

Fig. 2. $f_{h}$ solutions calculated for each pixel as a function of the DAIS band number.

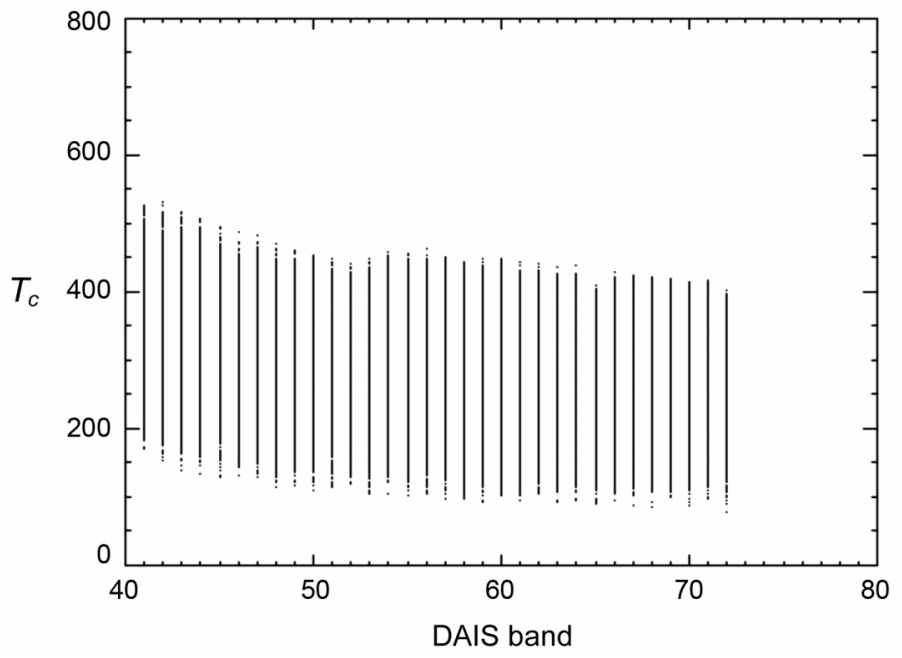

Fig. 3. $T_{c}$ solutions calculated for each pixel as a function of the DAIS band number.

Moreover the deviation from $\left\langle f_{h}\right\rangle$ rises to $0.005 \%$ for the first six SWIR-2 bands and band 60 shows an anomalous deviation.

With regard to the crustal temperature $T_{c}-<T_{c}>$, fig. 5 displays a maximum deviation of about $\pm 50^{\circ} \mathrm{C}$, except for the first six bands and for band 60 where the maximum deviation approximately increases twofold.

The dual band algorithm applied to the lava pool area selected by masking the DAIS image can or cannot converge to a solution. The histogram in fig. 6 shows the pixel number of the 
image where no solution was found for the system. When the system converges to a possible solution (considering the whole set of results) it is possible to accept or reject the estimated temperature and the fractional area values.

The $\left(T_{c}, f_{h}\right)$ estimated solutions statistics has been calculated for every pixel.
For a specified band of the SWIR-2 spectrometer, a pixel can be either rejected or accepted, this choice depends on the existence or not existence of anomalous $\left(T_{c}, f_{h}\right)$ values when Chauvenet criteria are applied.

Figures 7 and 8 show the histograms of the rejected and accepted pixels as functions of the

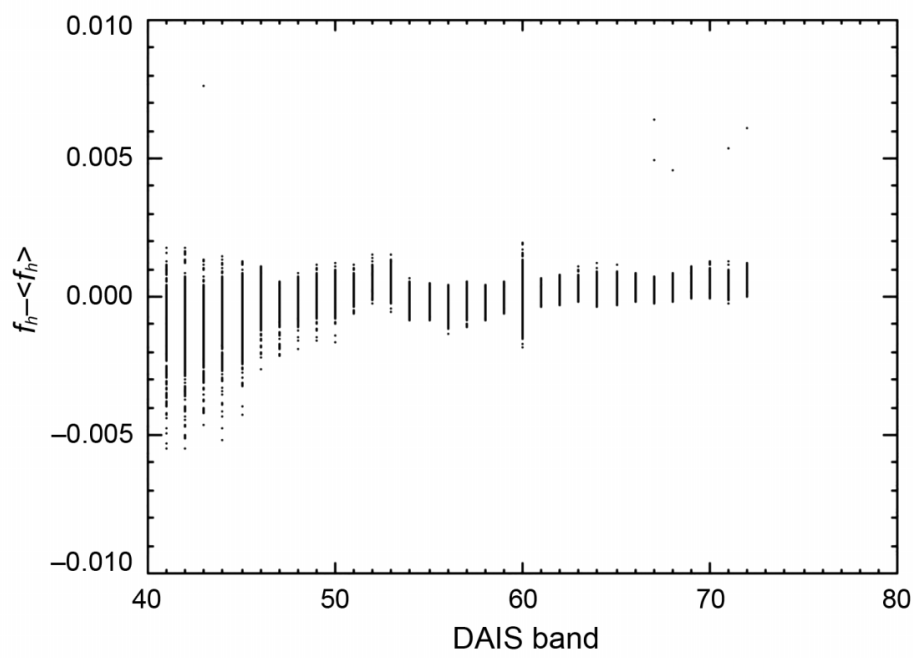

Fig. 4. $f_{h}-<f_{h}>$ deviation: $<f_{h}>$ is calculated for each pixel.

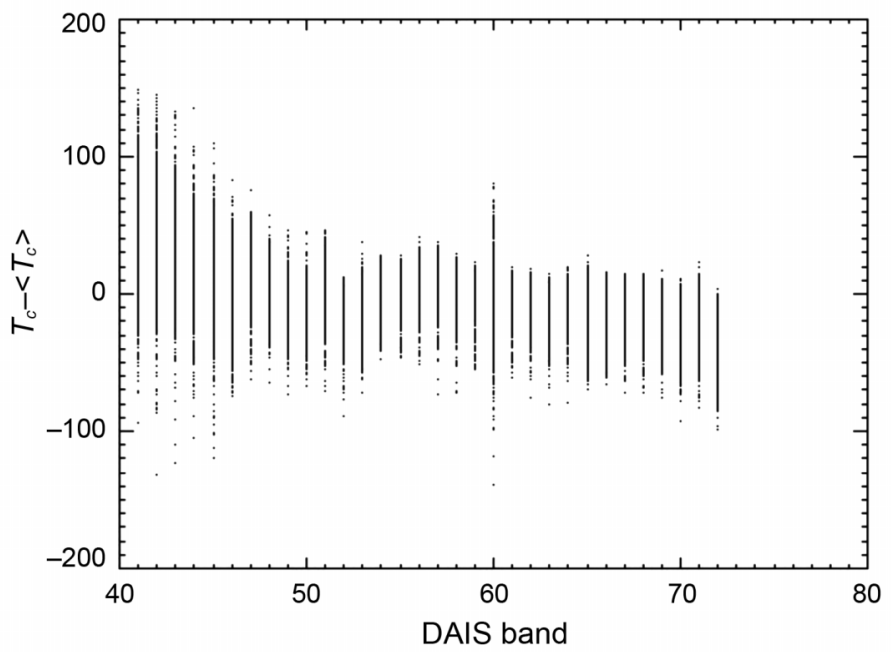

Fig. 5. $T_{c}-<T_{c}>$ deviation. 
DAIS bands corresponding to the SWIR-2 sensor. Once again these figures point out that the $\left(T_{c}, f_{h}\right)$ estimations of the first six channels of the SWIR-2 sensor are not reliable. This occurs because these channels are highly affected by water vapor absorption: as shown in fig. 9 the center band wavelengths reported in table II for the first six SWIR-2 channels fall at the edge of the water vapor window around 1.9 and 2.0 $\mu \mathrm{m}$.

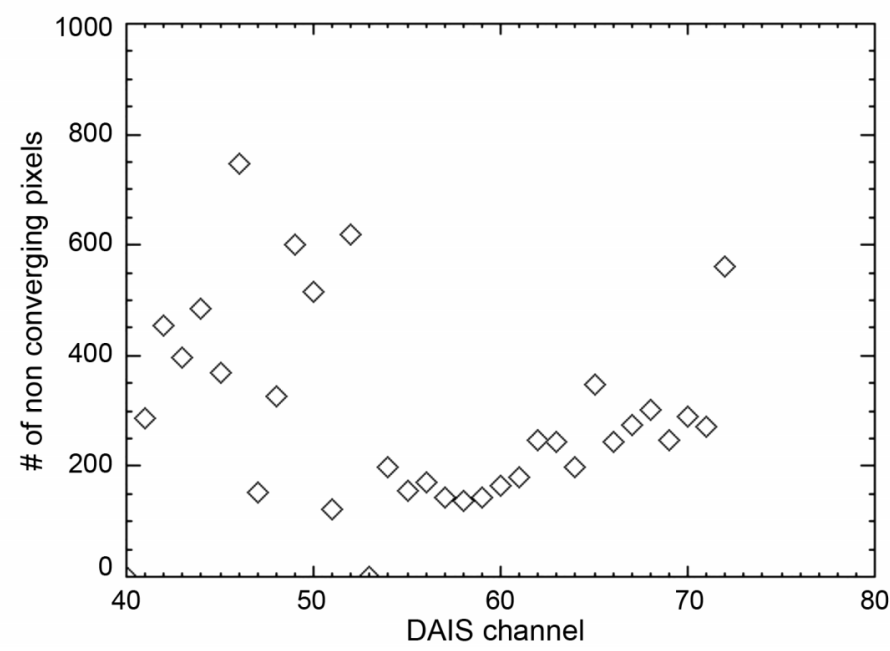

Fig 6. Histogram of the number of pixels in the case of no solutions from DB algorithm.

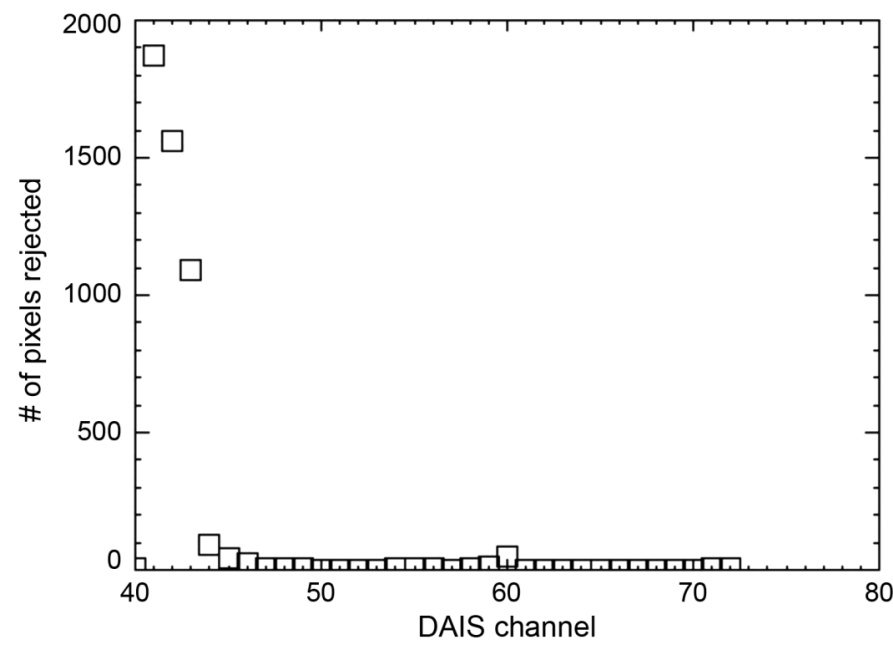

Fig. 7. Histogram of the number of pixels where the DB algorithm does give solutions, but pixels are rejected by the chosen selection criteria. The rejected pixels are concentrated in the first channels of the third spectrometer. 


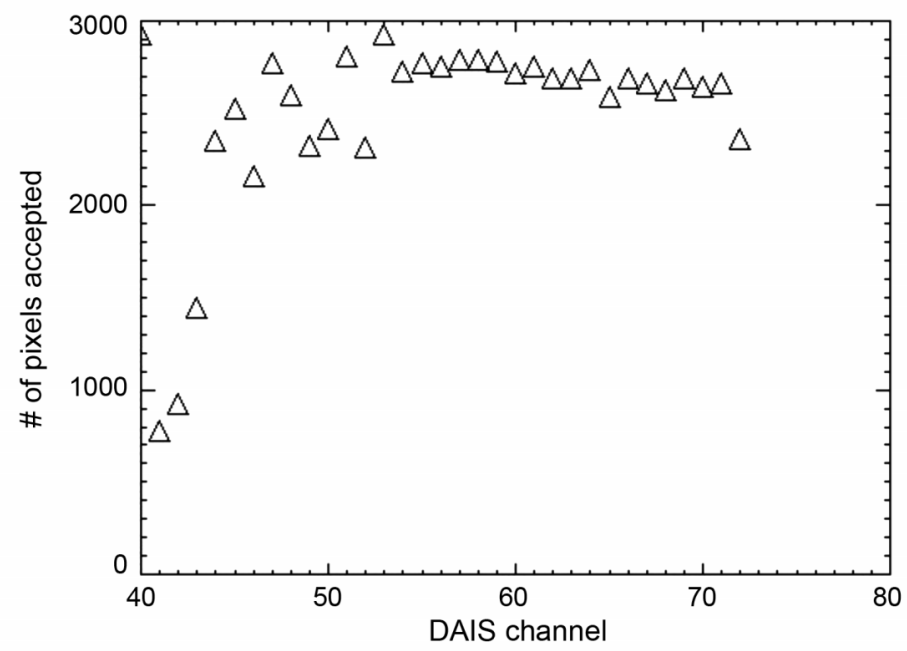

Fig. 8. Histogram of the number of pixels where the DB algorithm does give solutions and pixels are accepted by the chosen selection criteria.

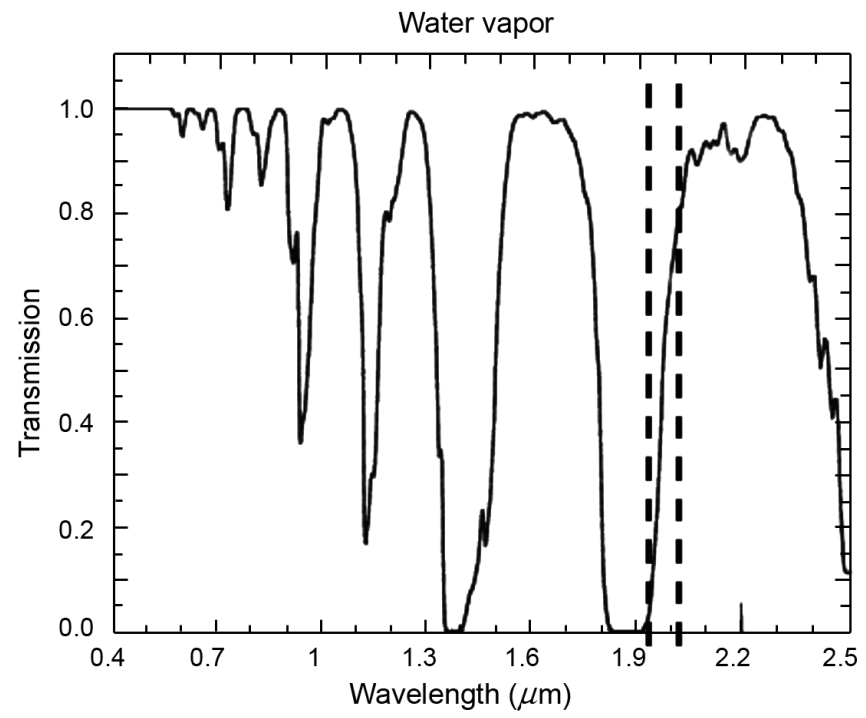

Fig. 9. DAIS bands involved in water vapor absorption range.

\section{Conclusions}

This work represents a first attempt to understand the influence of band choice in the dual band algorithm applied to the study of the thermal properties of a lava flows by means of remote sensing images. The hyperspectral technology now available on airborne and space borne sensors yields a SWIR bands much wider range if compared with the Landsat TM or the 
AVHRR. The analysis presented here is referred to the image collected by the DAIS air borne spectrometer on July 161996 on Mt. Etna (Sicily). A good stability was found in the estimation of the crustal temperature and fractional area provided by the dual band algorithm for all the band pairs possible selections from the second and third spectrometers of the DAIS sensor. An exception to this result was pointed out for the first six bands of the third DAIS spectrometer due to the water vapor absorption in that wavelength range. The 60th band that is also in the third spectrometer gave unreliable estimations due to an exceedingly noisy signal. The increasing $f_{h}$ and the corresponding decreasing $T_{c}$ trends when represented against the DAIS band number, that is the wavelength, needs to be better understood. Possible influences of the emissivity in the SWIR range, contribution of the reflectance and atmospheric correction will be the matter of further investigations.

\section{REFERENCES}

Archambault, C. and J.C. Tanguy (1976): Comparative temperature measurements on Mount Etna lavas: problems and thecniques, J. Volcanol. Geotherm. Res., 1, 113-125.

Calvari, S., M. Coltelli, M. Neri, M. Pompilio and V. SCRIBANO (1994): The 1991-1993 Etna eruption: chronology and geological observations, Acta Vulcanol., 4, 1-14.

Chester, D.K., A.M. Duncan, J.E. Guest and C.R.J. KILBURN (1985): Mount Etna: the Anatomy of a Volcano (Stanford University Press), pp. 404.

CRISP, J. and S. BAlogA (1990): A model for lava flows with two thermal componets, J. Geophys. Res., 95, 1255-1270.

DozIER, J. (1981): A method for satellite identification of surface temperature fields of subpixel resolution, $\mathrm{Re}$ mote Sensing Environ., 11, 221-229.
FLYNN, L.P., A.J.L. HARRIS and R. Wright (2001): Improved identification of volcanic features using Landsat 7 ETM+, Remote Sensing Environ., 78, 180-193.

GNV (1996): Global Volcanism Network (GNV), Etna, Smithson. Inst. Bull. Global Volcan. Network, 07/96 (BGVN 21:07).

GNV (1999): Global Volcanism Network (GNV), Etna, Smithson. Inst. Bull. Global Volcan. Network, 06/99 (BGVN 24:06).

Harris, A.J.L., L.P. Flynn, D.A. Rothery, C. OppenHEIMER and S.B. SHERMAN (1999): Mass flux measurements at active lava lakes: implications for magma recycling, J. Geophys. Res., 104, 7117-7136.

OPPENHEIMER, C. (1991): Lava flow cooling estimated from Landsat Thematic Mapper infrared data: the Lonquimay eruption (Chile, 1989), J. Geophys. Res., 96, 21865-21878.

OPPENHEIMER, C. (1993a): Infrared surveillance of crater lakes using satellite data, J. Volcanol. Geotherm. Res., 55, 117-128.

OPPENHEIMER, C. (1993b): Thermal distributions of hot volcanic surfaces constrained using three infrared bands of remote sensing data, Geophys. Res. Lett., 20 (6), 431434.

OpPenheimer, C., P.W. Francis, D.A. Rothery, R.W.T. CARLton and L. Glaze (1993a): Infrared image analysis of volcanic thermal features: Làscar Volcano, Chile, 1984-1992, J. Geophys. Res., 98, 4269-4286.

OPPENHEIMER, C., D.A. ROTHERY and P.W. FRANCIS (1993b): Thermal distribution at fumarole fields: implications for infrared remote sensing of active volcanoes, J. Volcanol. Geotherm. Res., 55, 97-115.

OpPenheimer, C., D.A. Rothery, D.C. Pieri, M.J. Abrams and V. CARRERE (1993c): Analysis of Airborne Visible/ Infrared Imaging Spectrometer (AVIRIS) data of volcanic hot spots, Int. J. Remote Sensing, 14 (16), 29192934.

PIERI, D.C., L.S. Glaze and M.J. Abrams (1990): Thermal radiance observation of an active lava flow during th June 1984 eruption of Mt. Etna, Geology, 18, 10181022.

Wooster, M.J., T. Kaneko, S. NAKada and H. Shimizu (2000): Discimination of lava dome activity styles using satellite-derived thermal structurs, J. Vulcanol. Geotherm. Res., 102, 97-118.

Wright, R., P.F. FlYNN and A.J.L. HARRIS (2001): Evolution of lava flow-fields at Mount Etna, 27-28 October 1999, observed by Landsat 7 ETM+, Bull. Vucanol., 63, 1-7. 